\title{
Unilateral magnetic stimulation of the phrenic
}

\section{nerve}

Gary H Mills, Dimitris Kyroussis, Carl-Hugo Hamnegard, Simon Wragg, John Moxham, Malcolm Green

\begin{abstract}
Background - Electrical stimulation of the phrenic nerve is a useful non-volitional method of assessing diaphragm contractility. During the assessment of hemidiaphragm contractility with electrical stimulation, low twitch transdiaphragmatic pressures may result from difficulty in locating and stimulating the phrenic nerve. Cervical magnetic stimulation overcomes some of these problems, but this technique may not be absolutely specific and does not allow the contractility of one hemidiaphragm to be assessed. This study assesses both the best means of producing supramaximal unilateral magnetic phrenic stimulation and its reproducibility. This technique is then applied to patients.
\end{abstract}

Methods - The ability of four different magnetic coils to produce unilateral phrenic stimulation in five normal subjects was assessed from twitch transdiaphragmatic pressure (TwPDI) measurements and diaphragmatic electromyogram (EMG) recordings. The results from magnetic stimulation were compared with those from electrical stimulation. To determine whether the magnetic field affects the contralateral phrenic nerve as well as the intended phrenic nerve, EMG recordings from each hemidiaphragm were compared during stimulation on the same side and the opposite side relative to the recording electrodes. The EMG recordings were made from skin surface electrodes in five normal subjects and from needle electrodes placed in the diaphragm during cardiac surgery in six patients. Similarly, the direction of hemidiaphragm movement was evaluated by ultrasonography. To determine the usefulness of the technique in patients the $43 \mathrm{~mm}$ mean diameter double coil was used in 54 patients referred for assessment of possible respiratory muscle weakness. These results were compared with unilateral electrical phrenic stimulation, maximum sniff PDI, and TwPDI during cervical magnetic stimulation.

Results - In the five normal subjects supramaximal stimulation was established for eight out of 10 phrenic nerves with the $43 \mathrm{~mm}$ double coil. Supramaximal unilateral magnetic stimulation produced a higher TwPDI than electrical stimulation (mean (SD) $13.4(2 \cdot 5) \mathrm{cm} \mathrm{H}_{2} \mathrm{O}$ with $35 \mathrm{~mm}$ coil; $14 \cdot 1(3 \cdot 8) \mathrm{cm} \mathrm{H}_{2} \mathrm{O}$ with $43 \mathrm{~mm}$ coil;
$10.0(1 \cdot 7) \mathrm{cm} \mathrm{H}_{2} \mathrm{O}$ with electrical stimulation). Spread of the magnetic field to the opposite phrenic nerve produced a small amplitude contralateral diaphragm EMG measured from skin surface electrodes which reached a mean of $15 \%$ of the maximum EMG amplitude produced by ipsilateral stimulation. Similarly, in six patients with EMG activity recorded directly from needle electrodes, the contralateral spread of the magnetic field produced EMG activity up to a mean of $3 \%$ and a maximum of $6 \%$ of that seen with ipsilateral stimulation. Unilateral magnetic stimulation of the phrenic nerve was rapidly achieved and well tolerated. In the 54 patients unilateral magnetic TwPDI was more closely related than unilateral electrical TwPDI to transdiaphragmatic pressure produced during maximum sniffs and cervical magnetic stimulation. Unilateral magnetic stimulation eliminated the problem of producing a falsely low TwPDI because of technical difficulties in locating and adequately stimulating the nerve. Eight patients with unilateral phrenic nerve paresis, as indicated by a unilaterally elevated hemidiaphragm on a chest radiograph and maximum sniff PDI consistent with hemidiaphragm weakness, were all accurately identified by unilateral magnetic stimulation.

Conclusions - Unilateral magnetic phrenic nerve stimulation is easy to apply and is a reproducible technique in the assessment of hemidiaphragm contractility. It is well tolerated and allows hemidiaphragm contractility to be rapidly and reliably assessed because precise positioning of the coils is not necessary. This may be particularly useful in patients. In addition, the anterolateral positioning of the coil allows the use of the magnet in the supine patient such as in the operating theatre or intensive care unit.

(Thorax 1995;50:1162-1172)

Keywords: magnetic stimulation, diaphragm, phrenic nerve.

Phrenic nerve stimulation allows non-volitional assessment of diaphragm contractility in terms of diaphragmatic EMG activity and twitch transdiaphragmatic pressure (TwPDI). ${ }^{12}$ However, the phrenic nerves may prove difficult to locate during transcutaneous electrical stimulation. Reduced or absent PDI may result from abnormal muscle or nerve function, or failure 
to locate and stimulate the nerve. This can lead to diagnostic uncertainty and repeated attempts to locate and stimulate the phrenic nerves, which may be painful. The relatively less tightly focused or localised nature of the magnetic field during magnetic stimulation allows easier location of the phrenic nerves.

Magnetic stimulation was originally developed in its modern form as a technique to produce cortical stimulation but was too painful to apply clinically. Similowski et al investigated the possibility of magnetic stimulation of the phrenic nerves by placing a circular coil over the back of the neck. ${ }^{3}$ This produced a magnetic field that stimulated the phrenic nerve roots bilaterally but did not have any effects on the central nervous system. Cervical magnetic stimulation is relatively simple and well tolerated ${ }^{34}$ and is currently designed to produce bilateral phrenic discharge; unilateral lesions cannot therefore be localised by TwPDI measurements. Electromyograms can be recorded from the skin surface at the seventh intercostal space in the anterior axillary line, allowing individual phrenic nerves to be studied. However, these recordings primarily give information on the latency of transmission down the nerves, but not on the ability of the hemidiaphragm to generate pressure.

Cervical magnetic stimulation also stimulates the muscles of the upper rib cage and those supplied by the brachial plexus. Activation of these muscles may lead to the generation of electromyographic activity with a short latency, making the identification of compound muscle action potentials arising from the diaphragm itself very difficult. In addition, patients with anatomical deformities of the cervical spine or abnormally thick neck tissues are difficult to stimulate satisfactorily with presently available stimulators using a magnetic coil positioned on the posterior aspect of the neck.

We have therefore investigated unilateral magnetic stimulation of the phrenic nerves, with smaller coils positioned anterolaterally, over the phrenic nerve in the neck. Double rather than single coils were used to allow the resulting magnetic fields to summate where the two coils were linked, producing a small area of intense magnetic field production. This increased the chances of achieving supramaximal stimulation of a single phrenic nerve.

To establish the optimum size of the coil the performance of four different double coils of varying size $(20,25,35$, and $43 \mathrm{~mm}$ mean diameters) was examined in normal subjects to assess whether supramaximal phrenic stimulation could satisfactorily be achieved (table 1). Electrical TwPDI was compared with magnetic TwPDI and the specificity of stimulation in

Table 1 Comparison of features of the four double coils used in the study

\begin{tabular}{lllll}
\hline $\begin{array}{l}\text { Mean diameter } \\
(\mathrm{mm})\end{array}$ & No. of turns & $\begin{array}{l}\text { Inductance } \\
(\mu \mathrm{H})\end{array}$ & $\begin{array}{l}\text { Peak field } \\
(\text { Tesla })\end{array}$ & $\begin{array}{l}\text { Induced charge per } \\
\text { phase 10 mm } \\
\text { below the surface } \\
\left(\mu \mathrm{CC} / \mathrm{cm}^{2}\right)\end{array}$ \\
\hline 20 & 11 & $6 \cdot 75$ & $4 \cdot 3$ & $0 \cdot 3$ \\
25 & 15 & $10 \cdot 3$ & $5 \cdot 1$ & $0 \cdot 5$ \\
35 & 16 & $13 \cdot 6$ & $4 \cdot 5$ & $0 \cdot 6$ \\
43 & 14 & 16.6 & $3 \cdot 9$ & $0 \cdot 8$ \\
\hline
\end{tabular}

$\mu \mathrm{H}=$ microHenry $\mu \mathrm{C}=$ microCoulomb terms of the spread of the stimulus to the opposite phrenic nerves was examined. The effect of spread of the magnetic field on contralateral diaphragm movement was assessed by EMG recordings and by studying the direction of movement of both halves of the diaphragm with the aid of ultrasound.

The latency of phrenic nerve stimulation was measured in normal subjects using electrical phrenic stimulation and unilateral magnetic stimulation and the results were compared. To avoid early EMG activity from skin surface electrodes, which is sometimes seen as a result of stimulation of muscle groups other than the diaphragm, we also compared electrical and magnetic latencies in patients during cardiac surgery by placing needle electrodes in the diaphragm while the chest was open.

The $43 \mathrm{~mm}$ coil was then used in 54 patients referred for investigation of respiratory muscle function to assess the ease with which unilateral magnetic stimulation could be achieved, and to compare this with unilateral electrical stimulation. Among these subjects we identified eight with unilateral paralysis of the diaphragm and compared the results with electrical stimulation to allow direct comparison of unilateral magnetic stimulation with unilateral electrical stimulation in the assessment of isolated paralysis of the hemidiaphragm. We were also able to determine whether cross spread of magnetic stimulation from the contralateral phrenic nerve would impair the diagnostic usefulness of unilateral magnetic stimulation in this situation.

The results of magnetic stimulation were also compared with other measurements of diaphragm strength including maximum sniff pressures and cervical magnetic stimulation.

\section{Methods}

PRINCIPLES OF UNILATERAL MAGNETIC STIMULATION

An electrical field is induced in a conductor if it is placed in a changing magnetic field. The amplitude of the resultant electrical field depends on the rate of change of the magnetic field and the geometry of the conductor. If of sufficient power this electrical field can stimulate neuromuscular tissue. The centre of a single magnetic coil is an area of low magnetic field intensity whereas the highest intensity is along a line drawn halfway between, and concentric with, the inner and outer borders of the coil assembly. If two coils are placed together as a double coil, the field summates at the point where they meet, allowing some degree of focusing of the magnetic field, and hence the resulting electrical field. Larger coils allow a greater number of turns of copper wire to be incorporated within their structure which allows a greater magnetic field to be generated and a greater proportion of the maximum output of the Magstim will pass through the coil. The larger coils also cool more readily between stimulations allowing more frequent use. The double coil shape allows the coils to be placed easily on the side of the neck without being pushed away from the skin by bony structures. 
SUBJECTS

The study was approved by the local ethical committee and subjects gave informed consent. Five normal subjects and 54 patients consecutively referred for respiratory muscle tests, and six patients undergoing coronary artery surgery, were assessed. The subjects (other than those undergoing surgery) were studied lying on a bed with the backrest adjusted to 45 degrees above the horizontal, with their heads in a neutral position and the abdomen unbound. Occasional patients with severe orthopnoea were studied more upright. The surgical patients were studied supine on the operating table during surgery. No long acting muscle relaxants were used. In this group needle electrodes were placed in the domes of the diaphragm and the phrenic nerves were magnetically and electrically stimulated transcutaneously on the anterolateral aspect of the neck. This allowed comparison of conduction times between the two techniques and assessed the effect of contralateral spread of the magnetic field to the opposite hemidiaphragm with the advantage that EMG activity could be sampled purely from the diaphragm, eliminating the possibility of contamination of the signal by other muscle groups.

\section{EQUIPMENT AND TECHNIQUES}

Transdiaphragmatic pressure was measured with a pair of balloon catheters cut to $110 \mathrm{~cm}$ (PK Morgan, Rainham, Kent, UK). These were passed pernasally following application of $4 \%$ topical lignocaine spray and $2 \%$ lignocaine anaesthetic gel to the nose. The tips of the catheters were positioned with the aid of continuous pressure monitoring in the oesophagus and stomach, respectively. The oesophageal pressure (POES) traces were observed as the catheter was withdrawn from the stomach. Once the PoEs became negative the catheter was withdrawn a further $10 \mathrm{~cm}$. To assess positioning the fall in POES was compared with the simultaneous change in mouth pressure when inspiration was attempted against a closed mouthpiece (which incorporated a small leak to prevent glottic closure). ${ }^{56}$ The gastric catheter was advanced to $70 \mathrm{~cm}$ and a positive deflection in the trace on inspiration or palpation of the abdomen was sought. Pressures were measured by Validyne MP43 transducers $\left( \pm 150 \mathrm{~cm} \mathrm{H}_{2} \mathrm{O}\right)$ and amplified by Validyne carrier amplifiers (Validyne Corporation, Northridge, CA, USA). These were calibrated before each study with a Universal Pressure Meter (BIO-TEK Instruments Inc., USA) which was regularly tested for accuracy with a water manometer.

The signals were passed to a 12 bit NB-MIO 16 analogue-digital board within a MacIntosh Centris 650 computer (Apple Computer Company, Cupertino, CA, USA) where the information was recorded and analysed using LabView 2.2 software (National Instruments, Austin, Texas, USA). A Magstim 200 (high power) magnetic stimulator was used to power the magnetic coils (Magstim Co., Whitland, Dyfed, UK). Electrical stimulation was per- formed with bipolar electrodes (Medelec Ltd, Old Woking, Surrey, UK) with the felt tips soaked in saline. The electrodes were connected to a constant voltage stimulator (Digitimer type 3072) and a gated pulse generator (Digitimer type 2521, Welwyn Garden City, Herts, UK) which produced square wave impulses of $100 \mu$ s duration.

In order to assess whether supramaximal stimulation of the phrenic nerves was achieved, the diaphragm electromyogram (EMG) and TwPDI were recorded simultaneously in each subject. The diaphragm EMG was recorded from the skin surface. The skin was cleansed with alcohol and two electrodes (ARBO Ag/ $\mathrm{AgCl}$ ) and one earth plate were positioned a few millimetres apart on the anterior axillary line in the seventh intercostal space. In three subjects surface electrodes were also attached over the transversus abdominis laterally over the mid clavicular line at mid abdominal level, the upper rib cage in the mid clavicular line second intercostal space, and a similar level on the posterior chest wall. The EMG signals were passed via long leads to a Magstim Neurosign 2000 preamplifier and amplifier (Magstim Co., Whitland, Dyfed, UK) and displayed via a combined pressure and EMG recording programme based on LabView software with a recording frequency of $10000 \mathrm{~Hz}$ and on a storage oscilloscope.

Contralateral EMG signals were also recorded to detect activation of the contralateral phrenic nerve and hemidiaphragm during unilateral magnetic stimulation. This process was repeated during cardiac surgery using needle electrodes placed in each of the hemidiaphragms to allow recordings during unilateral magnetic and electrical stimulation. Stimulations were once again made by applying the coil to the anterolateral surface of the neck over the phrenic nerve.

To further assess the impact of this cross activation and whether bilateral descent of the hemidiaphragms could occur during unilateral stimulation, the movement of the ipsilateral and the contralateral hemidiaphragm was measured five times on each side by ultrasound in three of the normal subjects during maximal unilateral magnetic stimulation with the magnetic stimulator set on $100 \%$ power using the largest two coils. An Acuson 128 ultrasound machine was used in $\mathrm{M}$ mode with a $3.5 \mathrm{MHz}$ phased array.

\section{PROCEDURE}

Normal subjects

Four double coils of various mean diameters $(20,25,35$, and $43 \mathrm{~mm})$ were used to stimulate the phrenic nerves at the posterior border of the sternomastoid muscle at the level of the cricoid cartilage in the five normal subjects (fig 1). The Magstim magnetic stimulator was charged to a range of predetermined percentages of maximum power output $(30,40$, $50,60,70,80,90,95$, and $100 \%$ ). Three stimulations were made on each side of the neck on each power setting with each coil in random order. Preliminary focusing to achieve optimum phrenic nerve stimulation was required with the two smallest coils. 


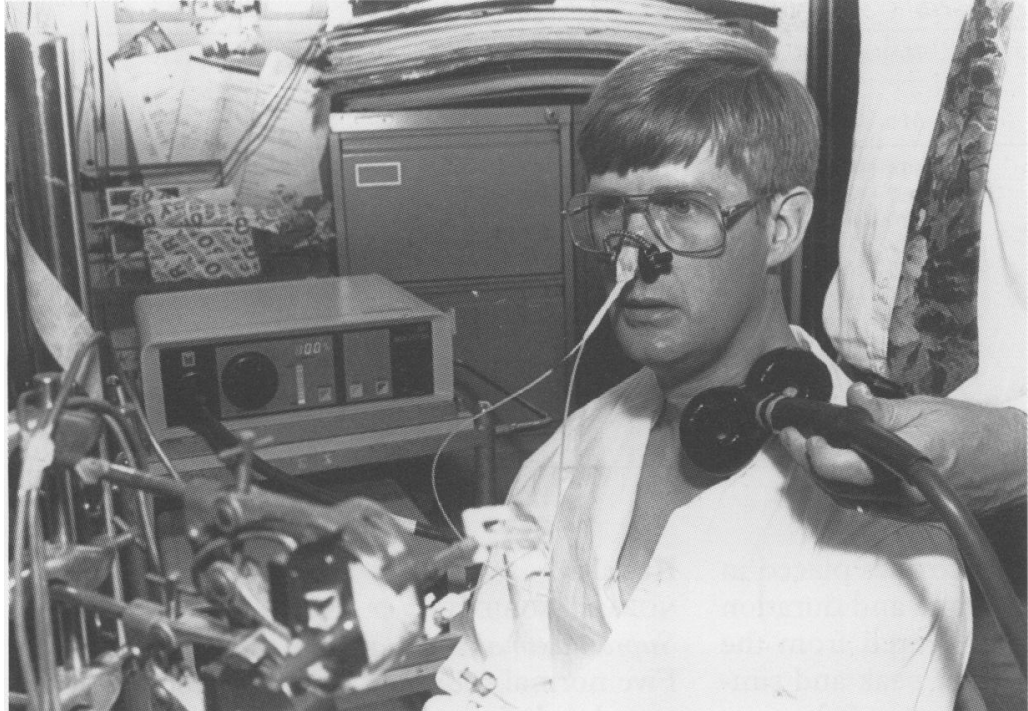

Figure 1 Unilateral magnetic stimulation of the phrenic nerve in a normal subject. Twitch pressures are measured from oesophageal and gastric balloons passed pernasally.

The recent contractile history of the diaphragm markedly influences transdiaphragmatic pressure responses to phrenic nerve stimulation. ${ }^{89}$ To avoid potentiation of the diaphragm there was a rest period of 20 minutes quiet breathing before the start of stimulation and a half minute interval between each magnetic twitch was used to ensure equal breaks between all stimulations. ${ }^{8}$

Similar recordings were made during unilateral electrical phrenic nerve stimulation. A ramp of increasing voltage of electrical stimulation was employed until no further increase in diaphragm EMG amplitude could be achieved. The order of the voltages employed was randomly varied. This allowed unilateral electrical and unilateral magnetic phrenic nerve stimulation to be compared. Twitch transdiaphragmatic pressure produced by the two techniques, together with the diaphragm EMGs, were measured. Supramaximal stimulation was indicated by the levelling off or "plateauing" of TwPDI and EMG amplitude in response to high stimulus intensities. The order of stimulation techniques was also randomly varied between unilateral electrical and unilateral magnetic stimulation.

Twitch responses were rejected for analysis when baseline oesophageal pressure immediately before stimulation was more than $1 \mathrm{~cm} \mathrm{H}_{2} \mathrm{O}$ different from that at functional residual capacity (FRC). ${ }^{10}$ Since monitoring of lung volumes is not possible with inductive plethysmography during magnetic stimulation because of displacement of the baseline by the magnetic field, we relied on POES as a measure of position in the respiratory cycle relative to FRC.

To exclude potentiation 10 baseline TwPDI measurements were made with cervical magnetic stimulation. Periodically, cervical magnetic stimulation measurements were repeated and compared with baseline results. If the cervical magnetic TwPDI was not within $15 \%$ of the mean baseline value the tests were repeated after a further rest period.
Supramaximal TwPDI during unilateral magnetic and unilateral electrical stimulation: The level of magnetic and electrical stimulator output required to produce supramaximal stimulation was assessed from the mean TwPDI and EMG amplitude response curves for the normal subjects. The TwPDI produced by the electrical and magnetic techniques at these power settings were compared with the Mann-Whitney $\mathrm{U}$ test. This allowed us to assess whether there was a significant difference in TwPDI produced by the different techniques at stimulator output levels which were likely to produce supramaximal phrenic activation.

Activation of the contralateral phrenic nerve by unilateral magnetic stimulation: Contralateral diaphragmatic EMG activity was assessed from skin surface electrodes in all five normal subjects with all four coils by using a ramp of stimulus intensities. The amplitude of EMG activity detected on the side of stimulation was compared with that seen when the contralateral phrenic nerve was stimulated but the EMG activity recorded from the original side.

To eliminate the possibility of muscle groups other than the diaphragm producing contralateral EMG activity we also measured diaphragm EMG amplitude from needle electrodes placed in the diaphragm muscle on both sides during cardiac surgery for coronary artery bypass grafting in patients who were otherwise fit, with no past history of disease that could affect nerve function. The needle electrodes were inserted into the domes of the diaphragm while the chest was open. The temperature of the hemidiaphragm was confirmed with a pair of needle thermocouples inserted close to the needle electrodes. This was done after rewarming to eliminate the effects of hypothermia on nerve function. No ice slush was used in these six patients. Patients were stimulated with the unilateral magnet. The amplitude recorded from electrodes on the same side as the initial stimulations was compared with that recorded by the same electrodes during contralateral phrenic stimulation at $100 \%$ power with the $43 \mathrm{~mm}$ coil. To minimise the influence of muscle blocking agents all subjects were intubated using suxamethonium, a very short acting muscle relaxant. No further relaxants were used during the surgery.

Latency of phrenic nerve conduction: The latency of conduction was recorded from the left side in all five normal subjects during electrical and magnetic stimulation. Three magnetic stimulations were made at each stimulus intensity from $50 \%$ to $100 \%$ of maximum power with each coil on each patient. Similarly, electrical stimulation was performed at 60,100 , 160 , and 180 volts on each subject. The dependence of latency on stimulus technique, intensity, and coil size was investigated.

To investigate the relationship between phrenic nerve conduction time seen with unilateral magnetic and unilateral electrical stimulation and to eliminate contamination of the EMG by the activity of other muscle groups, we stimulated six subjects during cardiac surgery and measured diaphragmatic EMG ac- 
Table 2 General and clinical characteristics of the patients and normal subjects

\begin{tabular}{|c|c|c|c|c|c|}
\hline \multicolumn{2}{|c|}{ Sex } & \multirow{2}{*}{$\begin{array}{l}\text { Mean (range) } \\
\text { age (years) }\end{array}$} & \multicolumn{2}{|l|}{ Height $(\mathrm{cm})$} & \multirow[t]{2}{*}{ Diagnosis/symptom } \\
\hline$M$ & $F$ & & Men (range) & Women (range) & \\
\hline $\begin{array}{l}4 \\
4 \\
1 \\
1 \\
9 \\
2 \\
0 \\
0 \\
2 \\
6 \\
4 \\
5\end{array}$ & $\begin{array}{l}0 \\
3 \\
1 \\
0 \\
4 \\
3 \\
2 \\
2 \\
3 \\
2 \\
1 \\
0\end{array}$ & $\begin{array}{l}57(37-53) \\
48(37-53) \\
66(58-73) \\
34 \\
55(43-72) \\
45(24-56) \\
65(58-71) \\
41(39-43) \\
57(36-58) \\
55(34-75) \\
52(31-64) \\
39(33-50)\end{array}$ & $\begin{array}{l}174(170-177) \\
167(166-168) \\
190 \\
180 \\
173(160-183) \\
171(169-172) \\
=- \\
\overline{17}(\overline{(166-178)} \\
176(171-181) \\
171(166-178) \\
180(173-198)\end{array}$ & $\begin{array}{l}\overline{169} \overline{(173-175)} \\
153 \\
\overline{159}(\overline{(155-170)} \\
166(161-176) \\
161(155-166) \\
157(150-163) \\
161(158-163) \\
160(159-161) \\
170 \\
-\quad-\end{array}$ & $\begin{array}{l}\text { Bilateral diaphragmatic paralysis } \\
\text { Cushing's syndrome } \\
\text { Kyphoscoliosis } \\
\text { Lyme disease } \\
\text { Motor neurone disease } \\
\text { Myopathies } \\
\text { Systemic sclerosis } \\
\text { Systemic lupus erythematosus } \\
\text { Unexplained dyspnoea } \\
\text { Unilateral hemidiaphragm paralysis } \\
\text { Various } \\
\text { Normals }\end{array}$ \\
\hline
\end{tabular}

tivity directly from needle electrodes placed in the diaphragm. Conduction time and duration of the action potential as measured from the start of the complex to the first peak and similarly to the second peak were recorded.

Variability: The between-occasion and within-occasion variabilities of the transdiaphragmatic pressures with the magnetic and electrical technique were assessed in the five normal subjects. Ten stimulations were made with each coil at $100 \%$ of maximum power plus $90 \%$ and $95 \%$ with the $43 \mathrm{~mm}$ magnet. Each subject was electrically stimulated 10 times at 180 volts. All these measurements were made on the left side to exclude side to side differences. This procedure was repeated on a second occasion.

\section{Patients referred for assessment of respiratory muscle strength}

Transdiaphragmatic pressure and diaphragm EMGs were recorded during unilateral magnetic stimulation with the $43 \mathrm{~mm}$ coil and during electrical stimulation in 54 consecutive patients referred for assessment of respiratory muscle strength (table 2). The unilateral magnetic and electrical TwPDI values corresponding to the plateau of the EMG amplitude or, if a plateau was not achieved, the largest amplitude obtained were recorded. The values obtained for the left and right sides were summed for each technique in each subject to allow comparison with techniques that involved activation of both phrenic nerves. The assessment of diaphragm contractility both by unilateral magnetic and by unilateral electrical stimulation was compared with transdiaphragmatic pressure measured during a volitional test (maximum sniff PDI) ${ }^{11}$ and a nonvolitional test (cervical magnetic stimulation). ${ }^{3}$ In some patients the phrenic nerve could not be located electrically, in which case two experienced investigators attempted phrenic stimulation.

The TwPDI produced by unilateral magnetic and electrical stimulation was compared in the eight patients found to have probable hemidiaphragm paresis. The diagnosis of unilateral paresis was made from radiological findings (a significantly raised hemidiaphragm on the chest radiograph), combined with a maximum sniff PDI no lower than the range seen by Laroche et al in hemidiaphragm weakness ${ }^{12}$ and comparable to the unilaterally weak patients described by Mulvey et al. ${ }^{13}$

\section{Results}

NORMAL SUBJECTS

Supramaximal stimulation

Five normal subjects (10 phrenic nerves) were tested with the unilateral coils and the electrical technique. Table 3 shows how many of the 10 phrenic nerves were judged to have been supramaximally stimulated by each of the different methods as assessed by levelling off of the TwPDI and EMG response in those individuals. Supramaximal stimulation was achieved most frequently with the $43 \mathrm{~mm}$ and $25 \mathrm{~mm}$ coils and the electrical stimulus. Supramaximal unilateral magnetic stimulation was seen in eight of the 10 phrenic nerves with the $43 \mathrm{~mm}$ coil when transdiaphragmatic pressure was compared with stimulus intensity, and in seven of the 10 phrenic nerves as judged from EMG amplitude.

The mean EMG response to the $35 \mathrm{~mm}$ and $43 \mathrm{~mm}$ coils tended to plateau with lower Magstim power outputs and, because the magnetic field was not intensely localised, the phrenic nerve could be stimulated easily with very little focusing even at relatively low powers (fig 2). However, TwPDI continued to rise slightly with increasing stimulus intensities, coincident with increasing spread of activation to the opposite phrenic nerve. The average amplitude of both PDI and EMG responses was less with the $20 \mathrm{~mm}$ and $25 \mathrm{~mm}$ coils (fig 3).

TwPDI during unilateral magnetic and electrical stimulation of the phrenic nerve

The mean EMG amplitude for each level of magnetic stimulator output on both left and right in all five normal subjects was assessed for each coil and similarly for electrical stimulation. The plateau of EMG response in the face of increasing levels of stimulation occurred at around $90 \%$ of maximum output for the $35 \mathrm{~mm}$ and $43 \mathrm{~mm}$ coil (fig 3). The levelling off of EMG response occurred at a mean (SD) TwPDI

Table 3 Frequency of successful supramaximal stimulation in 10 phrenic nerves judged by levelling off of twitch PDI or diaphragmatic EMG amplitude

\begin{tabular}{lll}
\hline Stimulus & TwPDI & EMG amplitude \\
\hline $43 \mathrm{~mm}$ & 8 & 7 \\
$35 \mathrm{~mm}$ & 7 & 5 \\
$25 \mathrm{~mm}$ & 8 & 6 \\
$20 \mathrm{~mm}$ & 2 & 3 \\
Electrical & 5 & 8 \\
\hline
\end{tabular}

F


EMG amplitude $v$ magnetic power output (35 mm coil)

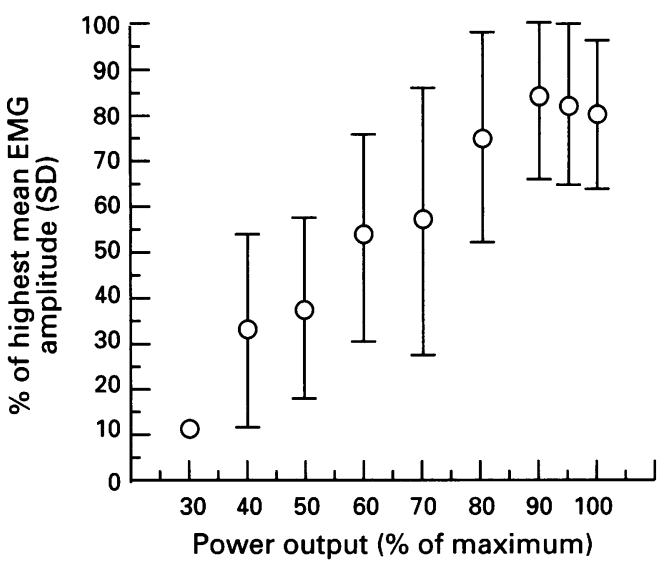

Twitch PDI $v$ magnetic power output (35 mm coil)

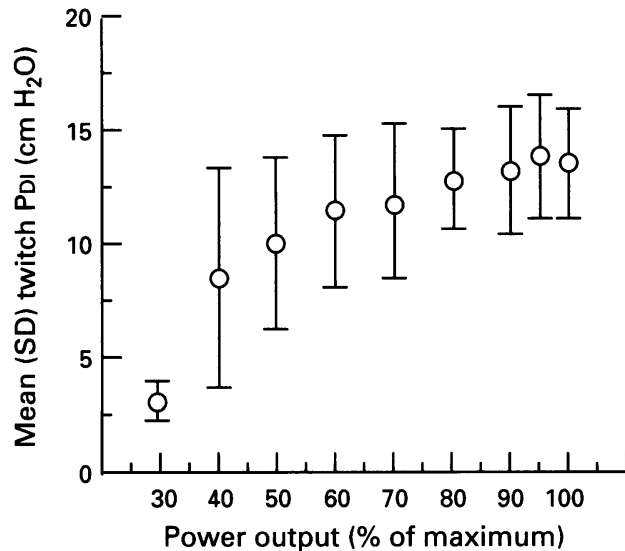

EMG amplitude $v$ magnetic power output (43 $\mathrm{mm}$ coil)

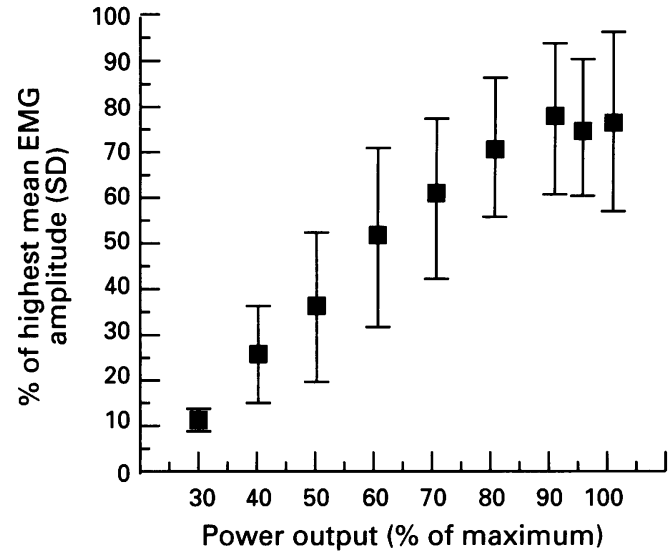

Twitch PDI $v$ magnetic power output

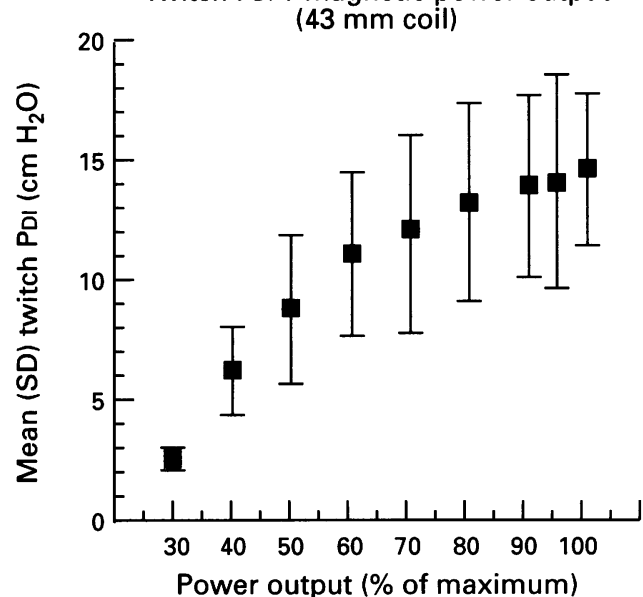

Figure 2 Amplitude of diaphragmatic EMG and twitch PDI compared with stimulus intensities for the $35 \mathrm{~mm}$ and $43 \mathrm{~mm}$ coils for five normal subjects. The EMG amplitudes are expressed as a percentage of the maximum EMG amplitude seen on any single occasion with any of the techniques when stimulating that side of the individual subject.

of $13 \cdot 4(2 \cdot 5) \mathrm{cm} \mathrm{H}_{2} \mathrm{O}$ for the $35 \mathrm{~mm}$ coil, $14 \cdot 1$ (3.8) $\mathrm{cm} \mathrm{H}_{2} \mathrm{O}$ for the $43 \mathrm{~mm}$ coil, and $10 \cdot 0$ $(1 \cdot 7)$ for the unilateral electrical technique.

Spread of the magnetic field to the opposite phrenic nerve

The larger the coil used and the higher the Magstim output, the greater the stimulation of the contralateral phrenic nerve as judged by

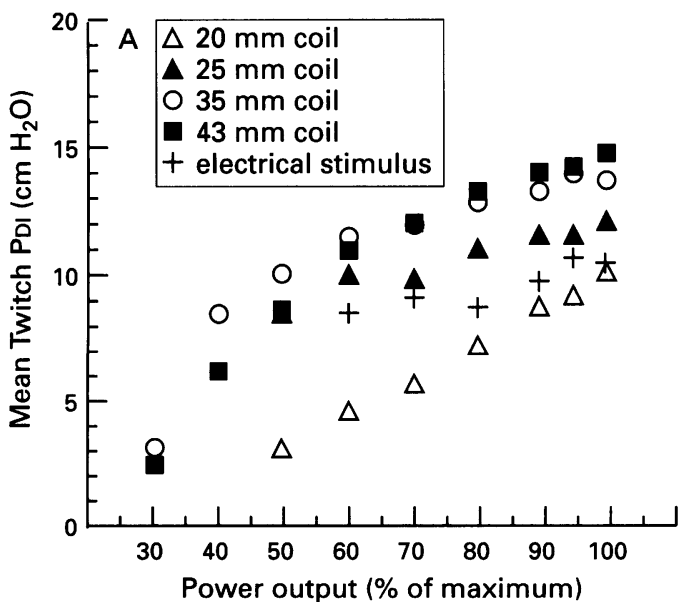

contralateral diaphragm EMG activity measured from surface electrodes (fig 4). This reached a mean (SD) amplitude of $13.9(6 \cdot 6) \%$ with the $43 \mathrm{~mm}$ coil at $100 \%$ stimulus intensity relative to the amplitude achieved when the phrenic nerve on the same side as the recording electrodes was directly stimulated.

Needle electrodes placed in the diaphragm during surgery showed less cross spread than with surface electrodes. The mean EMG amp-

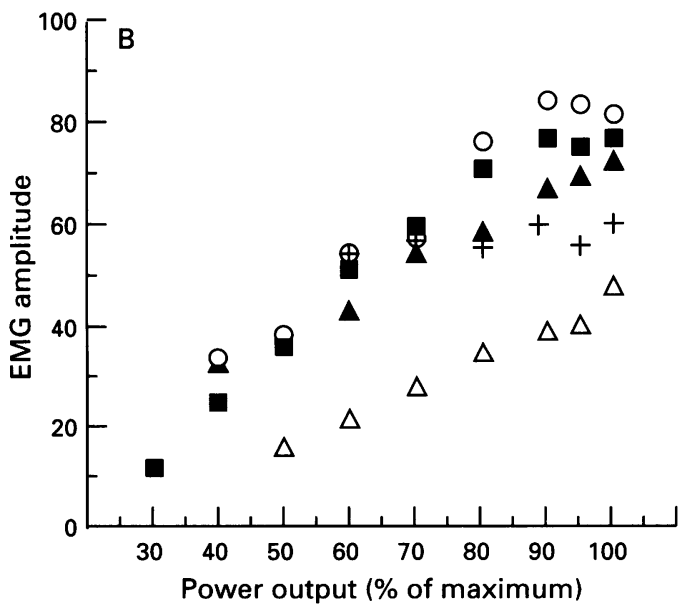

Figure 3 (A) Mean twitch PDI and (B) diaphragm EMG amplitude in normal subjects compared with stimulus intensity. (Electrical output is expressed as a percentage of 180 volts.) 


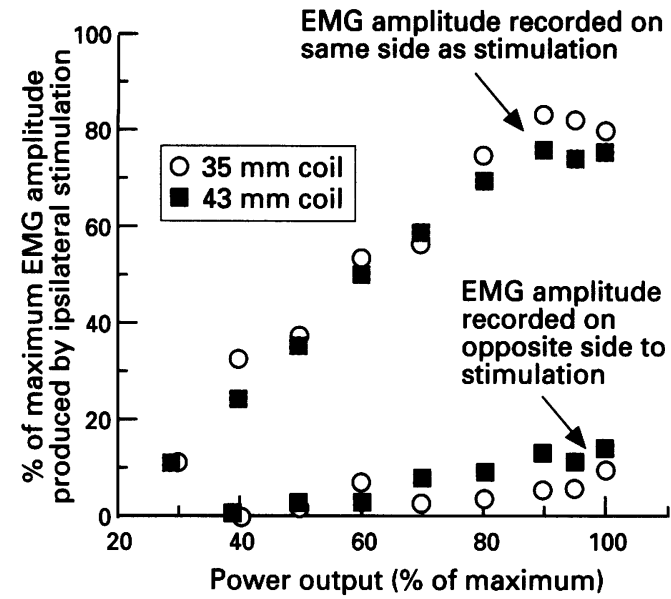

Figure 4 Relative EMG amplitudes produced by stimulation of the phrenic nerve on the same side as the recording electrodes and the contralateral side. (The mean EMG amplitude is expressed as a percentage of the maximum recorded.)

litude arising from the contralateral stimulation divided by that produced by stimulation on the same side as the recording electrodes was $3 \cdot 3$ $(1.9) \%$. The maximum relative amplitude produced by contralateral activation was $6.5 \%$.

Cross spread was found during electrical stimulation in one normal subject from skin surface electrodes, but this was of extremely low amplitude (less than $1 \%$ of that seen during ipsilateral stimulation).

\section{Ultrasonography of hemidiaphragm movement during unilateral magnetic stimulation of the phrenic nerve}

During all stimulations the ipsilateral hemidiaphragm movement was downward as expected, and the contralateral movement was upward. No attempt was made to quantify this movement.

\section{Latency}

A statistically significant average difference of $1 \mathrm{~ms}$ was seen between electrical $(7 \cdot 4(1 \cdot 6) \mathrm{ms})$

Table 4 Mean (SD) latency and duration of compound muscle action potentials during stimulation of the phrenic nerve with unilateral magnetic and unilateral electrical techniques in comnary artery surgery

\begin{tabular}{llll}
\hline Stimulus & Latency & $\begin{array}{l}\text { Time to } \\
\text { 1st peak } \\
(\mathrm{ms})\end{array}$ & $\begin{array}{l}\text { Time to } \\
\text { 2nd peak } \\
(\mathrm{ms})\end{array}$ \\
\hline $\begin{array}{l}\text { Unilateral } \\
\text { magnetic }\end{array}$ & $9 \cdot 1(0.7)$ & $2.9(0.5)$ & $7 \cdot 7(1.3)$ \\
$\begin{array}{l}\text { Unilateral } \\
\text { electrical }\end{array}$ & $8.8(0.8)$ & $3.3(0.5)$ & $7.6(1.8)$ \\
\hline
\end{tabular}

EMG activity recorded from needle electrodes in the diaphragm. Duration of the action potential measured from the start of the wave to the first peak and then the second peak.

Table 5 Comparison of mean (SD) twitch transdiaphragmatic pressure (TwPDI) during stimulation of left and right phrenic nerve in normal subjects

\begin{tabular}{llll}
\hline Stimulus & $\begin{array}{l}\text { Left } T w P D I \\
\left(c m \mathrm{H}_{2} \mathrm{O}\right)\end{array}$ & $\begin{array}{l}\text { Right TwPDI } \\
\left(\mathrm{cm} \mathrm{H} \mathrm{H}_{2} \mathrm{O}\right)\end{array}$ & $\begin{array}{l}\text { Difference between } \\
\text { lefi and right } T w P D I\end{array}$ \\
\hline Electrical & $11(2)$ & $9(2)$ & 2 \\
$35 \mathrm{~mm}$ coil & $14(2)$ & $13(2)$ & 1 \\
$43 \mathrm{~mm}$ coil & $16(3)$ & $12(4)$ & 4 \\
\hline
\end{tabular}

and magnetic stimulation $(6 \cdot 2(1 \cdot 8) \mathrm{ms})$ when latency was recorded from skin surface electrodes ( $p<0.0001$, unpaired $t$ test). No significant difference was seen when recording directly from needle electrodes in the diaphragm. No difference was seen in the duration of the action potential produced by electrical or magnetic stimulation when recorded from needle electrodes in the diaphragm (table 4).

\section{Activation of chest wall muscle groups}

In three normal subjects upper chest muscle activity was identified by EMG activity and by visible arm movements. Arm movements were also seen during electrical stimulation of the phrenic nerve. Similarly, sternomastoid activity occurred with both electrical and magnetic stimulation. During magnetic stimulation video recordings were made from lateral and anterolateral positions. These consistently showed an initial inward movement of the upper chest wall coincident with an expansion around the upper abdomen. Although inductive plethysmography with a Respitrace is affected by magnetic fields, it is possible to observe direction of chest and abdominal movement. Using a calibrated Respitrace during stimulation in three subjects an expansion at the upper abdominal level was seen immediately after the magnetic pulse, coinciding with a small inward upper chest movement (Respitrace Corp, Ardsley, NY, USA). These observations suggest that, although magnetic stimulation activates rib cage muscles and muscles acting on the upper chest, their action is not inspiratory. Instead the expansion occurs at the abdominal level, probably due to contraction of the diaphragm.

\section{Variability}

Reproducibility studies showed a withinoccasion variability of $8 \%$ or less with the 43 and $35 \mathrm{~mm}$ coils, and $10 \%$ with the electrical stimulation. When the stimulations were repeated on another occasion six weeks later and the means were compared with the initial results, the average difference between the mean TwPDI for all the subjects on the first and second occasion was $2 \mathrm{~cm} \mathrm{H}_{2} \mathrm{O}$ for the $43 \mathrm{~mm}$ coil, $0 \mathrm{~cm} \mathrm{H}_{2} \mathrm{O}$ for the $35 \mathrm{~mm}$ coil, and $0 \mathrm{~cm} \mathrm{H}_{2} \mathrm{O}$ for electrical stimulation.

\section{Pressure generation and variability}

Mean TwPDI and EMG amplitude for the five normal subjects began to level off in response to magnetic or electrical stimulator output at around $90 \%, 95 \%$, and $100 \%$ power output and at 120,140 , and 180 volts. When the TwPDI produced at these outputs was compared for the $35 \mathrm{~mm}$ coil, $43 \mathrm{~mm}$ coil, and electrical stimulation it was found that the TwPDI was greater in response to supramaximal unilateral magnetic stimulation than to electrical stimulation $\left(13.4(2.5) \mathrm{cm} \mathrm{H}_{2} \mathrm{O}\right.$ with the $35 \mathrm{~mm}$ coil, $14 \cdot 1(3 \cdot 8) \mathrm{cm} \mathrm{H}_{2} \mathrm{O}$ with the $43 \mathrm{~mm}$ coil, $10.0(2 \cdot 1) \mathrm{cm} \mathrm{H}_{2} \mathrm{O}$ with electrical stimulation, $\mathrm{p}<0.01)$. Left TwPDI was consistently 
Table 6 Variability of TwPDI in response to unilateral magnetic and electrical stimulation

\begin{tabular}{|c|c|c|c|c|c|}
\hline Stimulus & $\begin{array}{l}\text { Mean TwPDI on } \\
\text { occasion } 1\end{array}$ & $\begin{array}{l}\text { Coefficient of } \\
\text { variation on } \\
\text { occasion } 1\end{array}$ & $\begin{array}{l}\text { Mean TwPDI on } \\
\text { occasion } 2\end{array}$ & $\begin{array}{l}\text { Coefficient of } \\
\text { variation on } \\
\text { occasion } 2\end{array}$ & $\begin{array}{l}\text { Mean }(S D) \text { of } \\
\text { absolute differences } \\
\text { between occasions } 1 \\
\text { and } 2\end{array}$ \\
\hline $\begin{array}{l}180 \text { volts } \\
20 \mathrm{~mm}(100 \%) \\
25 \mathrm{~mm}(100 \%) \\
35 \mathrm{~mm}(100 \%) \\
43 \mathrm{~mm}(90 \%) \\
43 \mathrm{~mm}(95 \%) \\
43 \mathrm{~mm}(100 \%)\end{array}$ & $\begin{array}{l}12 \\
10 \\
14 \\
15 \\
17 \\
17 \\
17\end{array}$ & $\begin{array}{r}10 \% \\
17 \% \\
6 \% \\
8 \% \\
6 \% \\
6 \% \\
7 \%\end{array}$ & $\begin{array}{l}12 \\
12 \\
13 \\
15 \\
15 \\
15 \\
15\end{array}$ & $\begin{array}{r}10 \% \\
16 \% \\
12 \% \\
8 \% \\
8 \% \\
7 \% \\
7 \%\end{array}$ & $\begin{array}{l}1(3 \cdot 2) \\
1(4 \cdot 1) \\
1(3 \cdot 0) \\
0(2 \cdot 3) \\
2(2 \cdot 1) \\
1(2 \cdot 0) \\
2(3 \cdot 4)\end{array}$ \\
\hline
\end{tabular}

greater than right TwPDI for the electrical and magnetic techniques measured at the upper three stimulus intensities (table 5). This difference was not significant for the $35 \mathrm{~mm}$ coil but was significant $(p<0.01)$ for the electrical stimulus and the $43 \mathrm{~mm}$ coil.

The mean TwPDI and coefficient of variation for all coils and electrical stimulation was assessed on one side in the normal subjects on two separate occasions ranging 6-10 weeks apart. Ten stimulations were made in each subject at each power output, and the results are detailed in table 6 . The within-occasion coefficient of variation was calculated for all TwPDI measurements in each subject with each technique in turn. The average coefficient of variation was calculated for each technique across the group.

To assess how TwPDI measurements changed between the two occasions the mean TwPDI for each technique for each individual on the second occasion was subtracted from
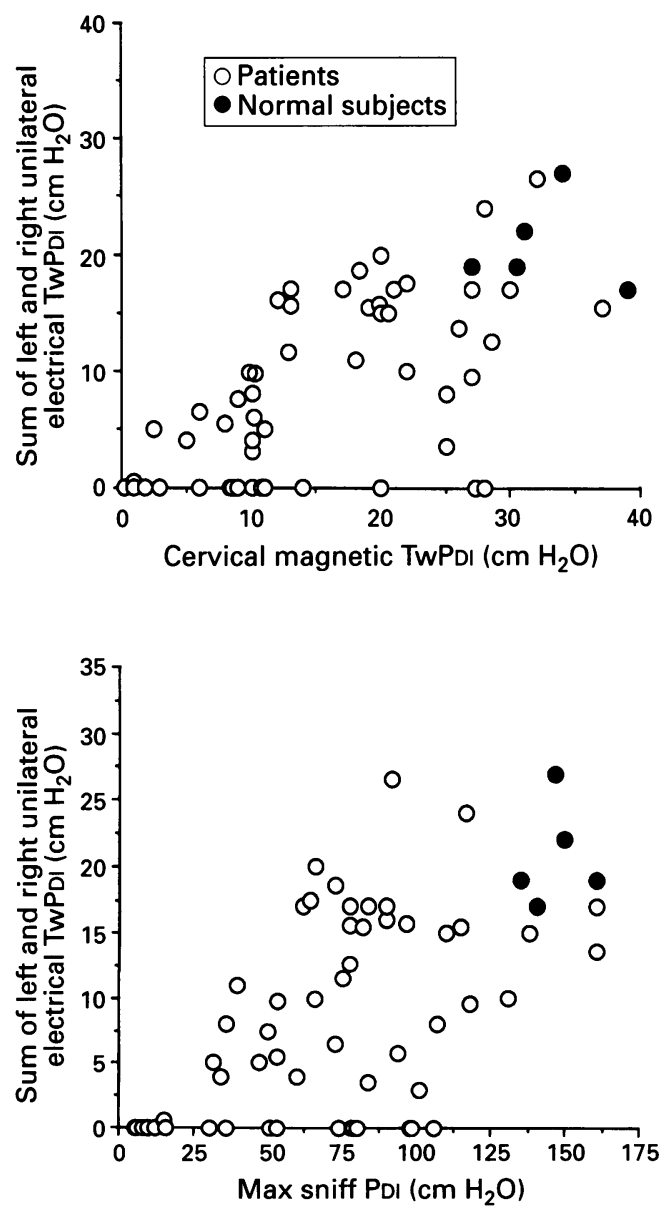

the results obtained on the first occasion and the absolute differences were noted. The mean and standard deviation of the absolute differences between the two occasions for each technique were calculated.

\section{PATIENTS REFERRED FOR ASSESSMENT OF} RESPIRATORY MUSCLE STRENGTH

Comparison of unilateral magnetic and unilateral electrical stimulation with maximum sniff PDI and cervical magnetic stimulation

The sum of the left and right unilateral magnetic TwPDI and the electrical responses were compared with the maximum sniff PDI and cervical magnetic TwPDI (fig 5). A closer relationship was seen between maximum sniff PDI and the unilateral magnetic technique than with electrical stimulation. Electrical stimulation produced lower or absent twitch pressures compared with those that would have been expected from the sniff data. This was not
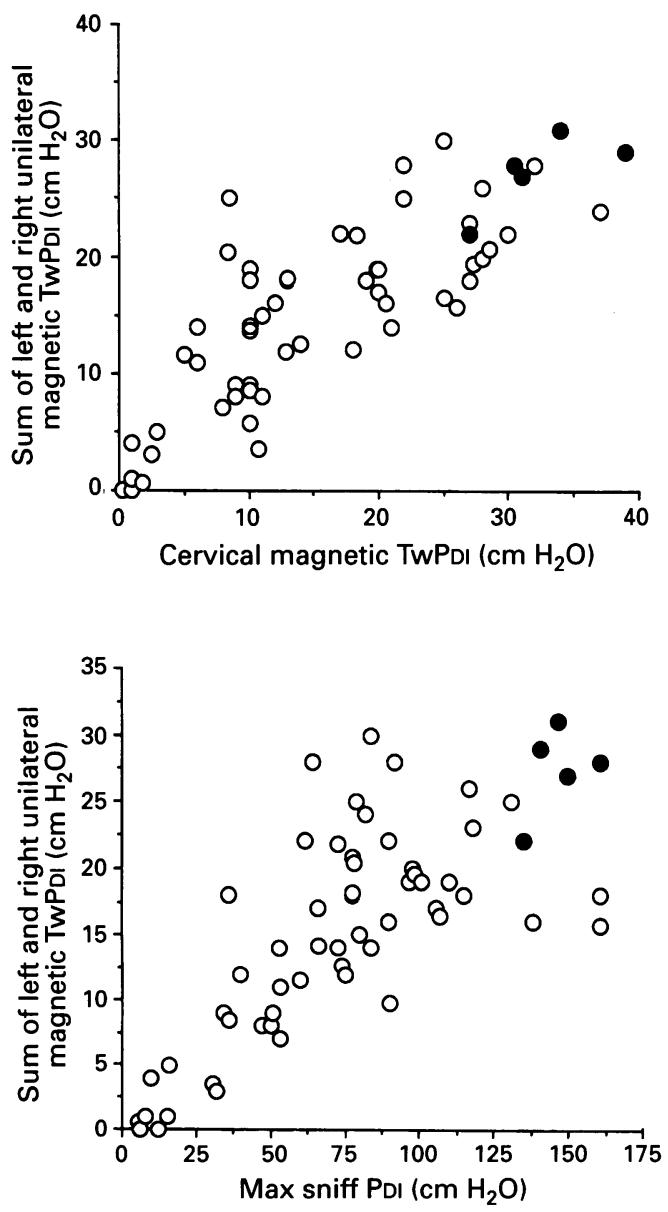

Figure 5 Twitch PDI produced by the $43 \mathrm{~mm}$ coil and by electrical stimulation in patients and normal subjects compared with maximum sniff PDI and twitch PDI during cervical magnetic stimulation. 


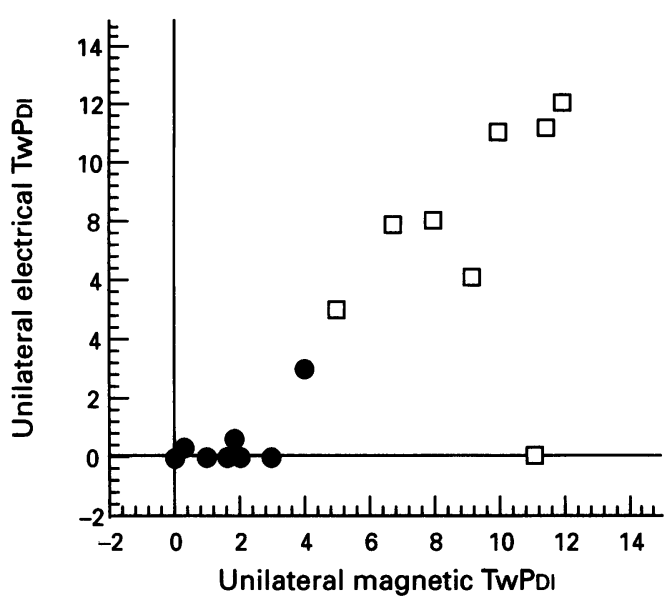

Figure 6 Unilateral magnetic and unilateral electrical TwPDI compared in eight subjects with unilateral paresis of the hemidiaphragm. = side of raised hemidiaphragm; $\square=$ side of normally positioned hemidiaphragm.

the case with unilateral magnetic stimulation where a low TwPDI was always accompanied by a low TwPDI during cervical magnetic stimulation. Unilateral magnetic stimulation is therefore a more reliable means of assessing diaphragm contractility than unilateral electrical stimulation of the phrenic nerve.

\section{Patients with unilateral diaphragm paresis}

Eight patients with unilateral phrenic nerve paresis were assessed with unilateral magnetic and unilateral electrical stimulation and the PDI responses were compared (fig 6). In seven of the patients the electrical twitch on the stronger side was within the normal range for unilateral electrical stimulation described by Mier and coworkers. ${ }^{14}$ In the eighth patient no electrical TwPDI could be produced on either side, despite maximum sniff PDI values suggestive of unilateral hemidiaphragm weakness.

Figure 7 shows the pressure responses seen with unilateral magnetic and electrical stimulation in a patient with unilaterally reduced hemidiaphragm contractility.

\section{Discussion}

In normal subjects the results of this study show that supramaximal unilateral stimulation of the phrenic nerve can be achieved magnetically and the resulting TwPDI is reproducible. Twitch PDI is greater with unilateral magnetic stimulation than with electrical stimulation. During magnetic stimulation there is activation of other muscle groups, particularly the opposite hemidiaphragm, although this is insufficient to produce descent of the hemidiaphragm opposite to the side of stimulation.

In patients the technique is easy to apply and is well tolerated, and produces results consistent with other techniques for assessing diaphragm contractility. Furthermore, the technique is useful in the confirmation of unilateral paresis of the hemidiaphragm.

Supramaximal stimulation is most commonly achieved with the $35 \mathrm{~mm}$ and $43 \mathrm{~mm}$ double coils which produced a plateau of response of EMG amplitude more readily and on lower powers than the other coils (figs 2 and 3). The broader area of high intensity of magnetic field reduced the difficulties of focusing on the phrenic nerve to a minimum. After initial studies the $43 \mathrm{~mm}$ coil was therefore selected for patient studies as the need for repeated stimulation to produce adequate phrenic nerve activation was minimised, despite the increasing tendency to produce a small amount of stimulation of the opposite phrenic nerve.

Twitch PDI is greater with magnetic stimulation than with electrical stimulation. The reason for the increased pressures appears to be the activation of other muscle groups. With magnetic stimulation, in addition to the ipsilateral diaphragm, there is also some activation of the upper chest wall muscles, sternomastoid, and the muscles supplied by the brachial plexus, together with some activation of the contralateral hemidiaphragm which can be confirmed from surface EMG recordings. However, this activity was not sufficient to produce an important change in transdiaphragmatic, oesophageal, or gastric pressure in the four patients who proved to have bilateral diaphragm paralysis in whom the mean unilateral TwPoes was less than $1 \mathrm{~cm} \mathrm{H}_{2} \mathrm{O}$. Any chest wall activation that was produced was therefore insufficient to produce an inspiratorylike action without the aid of the diaphragm. In the normal subjects no EMG activity could be recorded from the mid to lower abdominal wall, although contralateral hemidiaphragm activity was recorded. This was greater with high stimulator outputs and larger coils. When EMG amplitudes were compared the mean contralateral EMG reached $15 \%$ of the surface EMG amplitude that would have resulted if the magnet had been directly applied over the contralateral phrenic nerve, and a mean of $3.3 \%$ (maximum 6.5\%) when assessed by EMG amplitude directly from needle electrodes in the diaphragm during cardiac surgery. To analyse the consequences of this contralateral EMG activity, ultrasound studies of diaphragm movement were performed in three normal subjects to examine the direction of movement of both the ipsilateral and contralateral hemidiaphragm during unilateral magnetic stimulation. This indicated that the contralateral muscle activity was not sufficient to produce downward displacement of the hemidiaphragm. The action of the other muscles may have been to stiffen the walls of the thoracic cavity so enabling the ipsilateral hemidiaphragm to produce a TwPDI more efficiently.

The left-sided TwPDI values were consistently higher than the right-sided pressures. This finding has been noted previously. ${ }^{15}$

In common with Similowski $e t a l^{3}$ we found differences in latency between oesophageal and skin surface diaphragm EMG recordings during magnetic stimulation. This appeared to be due to a small extra peak appearing $4-5 \mathrm{~ms}$ after the stimulus which may be due to contamination of the EMG with electrical activity 
A

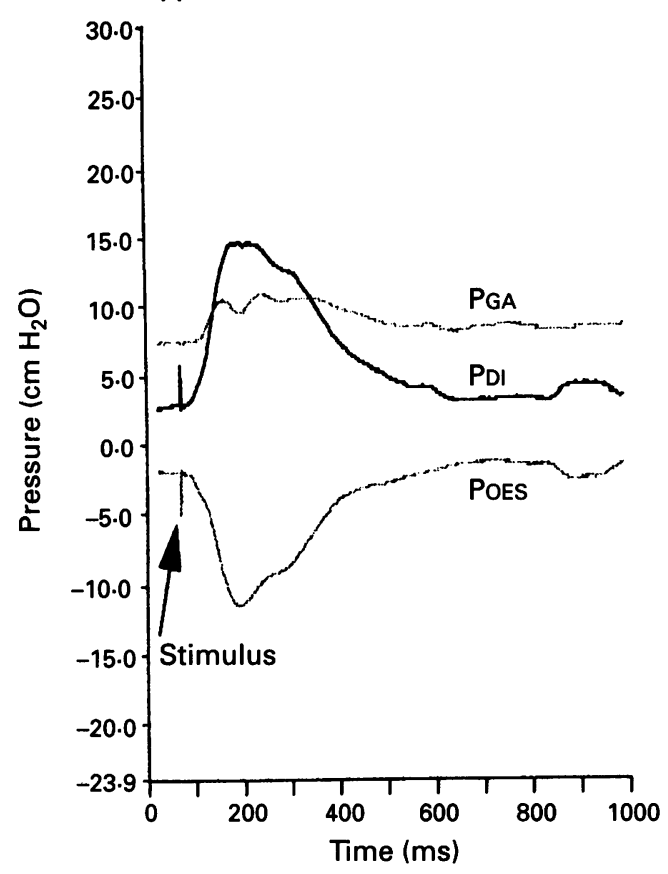

B

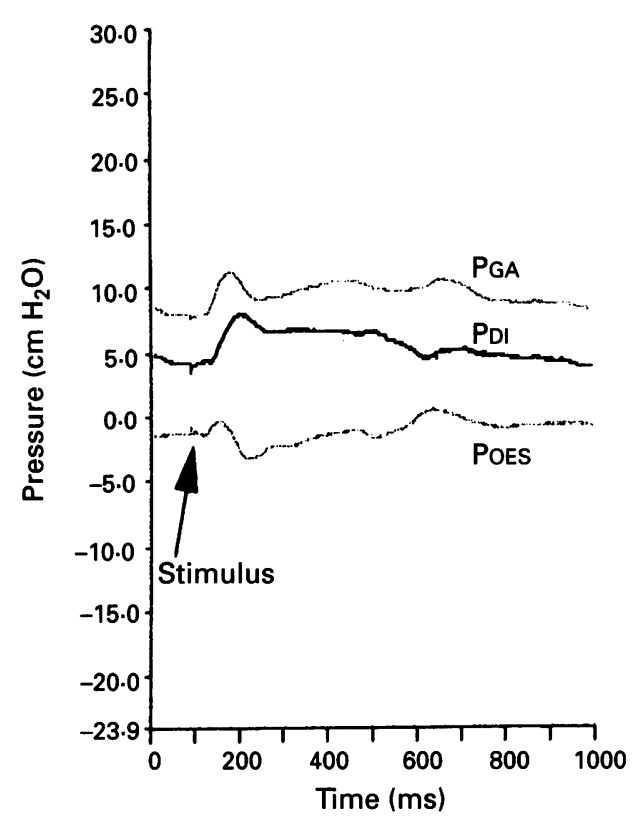

C
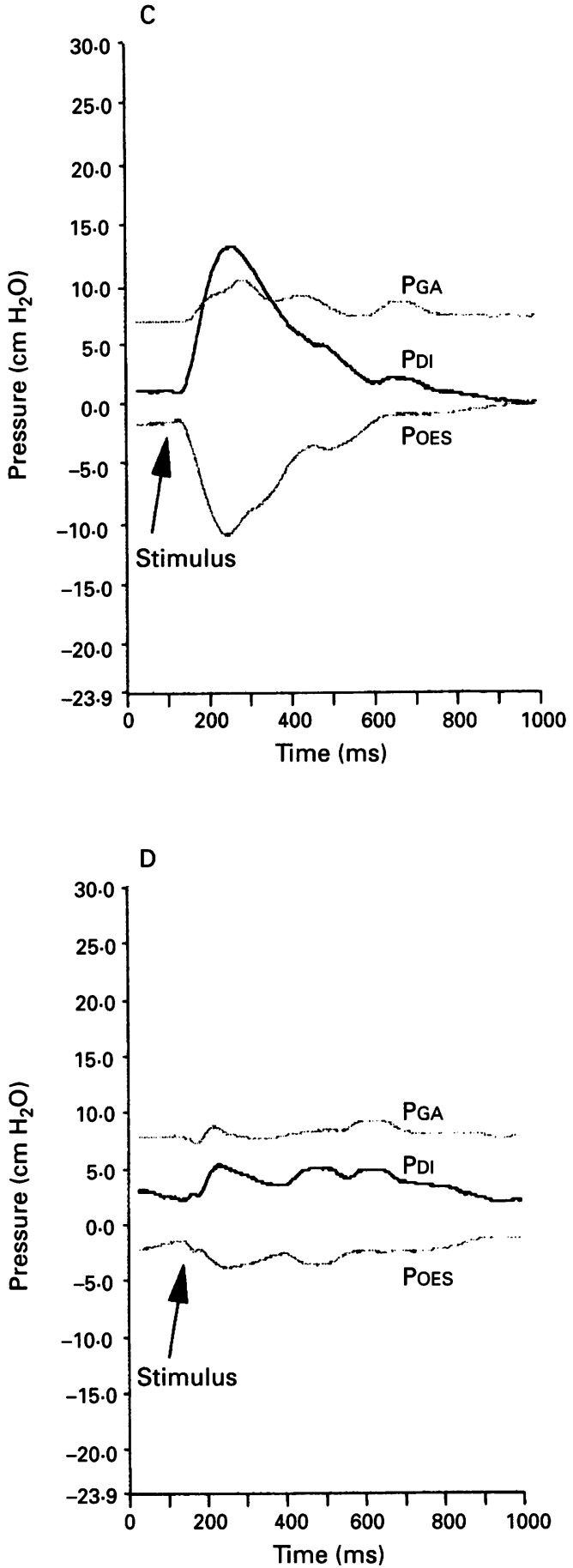

Figure 7 Pressure traces produced during unilateral magnetic stimulation of (A) a normal phrenic nerve and (B) an abnormal phrenic nerve, and electrical stimulation of $(C)$ a normal phrenic nerve and (D) an abnormal phrenic nerve in a patient with weakness of the hemidiaphragm due to herpes zoster affecting $C 3,4$, and 5 on one side.

arising from other muscle groups. This was a prominent feature in two of the five normal subjects, but not the other three.

As a result the magnetic latencies measured from skin electrodes were significantly different from those produced by electrical stimulation of the phrenic nerve. This was not the case in those subjects who were stimulated while their chests were open with needle electrodes inserted into the diaphragm. Here the latencies were very closely related (fig 3 ), suggesting that early activation of other muscle groups during magnetic stimulation in some normal subjects may contaminate the signal received by skin surface electrodes. This therefore impairs the usefulness of the unilateral magnetic technique in non-invasive phrenic nerve latency assessment in some subjects.

Pressure responses during electrical phrenic nerve stimulation are widely used to assess diaphragm function. ${ }^{1}$ However, accurate location of the phrenic nerve can be difficult, and failure to produce a TwPDI may be due to severe diaphragm weakness or failure to locate the nerve. If this occurs, repeated stimulations may be needed to clarify the situation and may be painful.

The greater ease of use of the magnetic technique was illustrated by the patient group, where a closer relationship was seen between 
sniff PDI and magnetic stimulation with the $43 \mathrm{~mm}$ coil than between sniff PDI and electrical stimulation. On some occasions electrical stimulation produced either no PDI or a low PDI relative to sniff pressures in patients. In these cases the unilateral magnetic stimulation proved more specific by producing a PDI more in keeping with that which would have been predicted from the sniff PDI. A similar situation occurred when the unilateral techniques were compared with cervical magnetic stimulation.

In the eight subjects with unilateral paresis of the hemidiaphragm a markedly reduced TwPDI was found on the side corresponding to the elevated hemidiaphragm in all cases. This was also the case with electrical stimulation. However, in one subject no twitch pressure could be identified on the apparently normal side using electrical stimulation, whereas TwPDI was normal with unilateral magnetic stimulation. Maximum sniff pressures in all eight subjects were within the range seen in paralysis of the hemidiaphragm, ${ }^{12}$ so the absent TwPDI in response to electrical stimulation on the side with normal radiographic findings was felt to be a false finding due to difficulties with electrical stimulation.

Unilateral magnetic phrenic nerve stimulation is a new technique for the assessment of diaphragm contractility. The magnetic fields require less precise focusing and are less impeded by the depth of tissue over the phrenic nerve than electrical stimulation. The technique is therefore easy to use and can produce supramaximal stimulation with the minimum of focusing. This removes the concern that the stimulator positioning may be inadequate, which is often a problem when a twitch response cannot be elicited with unilateral electrical stimulation.

The magnetic technique also allows phrenic stimulation in clinical situations where it may be difficult to position the patient or where there are problems with the adequacy of stimulation from cervical magnetic stimulation, such as in the presence of a "buffalo hump" in Cushing's syndrome, significant neck deformity, or in the operating theatre even if an internal jugular line is in situ. The ease of location of the phrenic nerve leads to a need for fewer stimulations and reduces patient discomfort and twitch potentiation. All but one of the 54 conscious patients reported that magnetic stimulation caused less discomfort than electrical stimulation.

Further development of smaller double coils, particularly with reference to depth of pen- etration and breadth of spread of the denser areas of the magnetic field, may allow a reduction in the stimulation of other nearby nerves. The ideal size of the double coil appears to lie between $35 \mathrm{~mm}$ and $43 \mathrm{~mm}$. To this end further development of a $40 \mathrm{~mm}$ double coil is under way to reduce the sideways spread of the magnetic field, while preserving adequate spread to maintain the ease of stimulation of the phrenic nerve and increasing the intensity of the centre of the field. The simultaneous use of two coils to allow bilateral phrenic nerve stimulation is likely to be a useful technique for the assessment of supine patients such as those in the intensive care unit.

We conclude that unilateral magnetic stimulation of the phrenic nerve is a useful technique which adds to the portfolio of non-volitional tests of diaphragm contractility, and is likely to be of considerable value in both the clinical assessment of patients and physiological studies, particularly where technical difficulties are encountered in adequately locating or stimulating the phrenic nerve with the electrical technique.

1 Mier A, Brophy C, Moxham J, Green M. Twitch pressures in the assessment of diaphragm weakness. Thorax 1989 ; in the assess $44: 990-6$.

2 Bellemare F, Bigland-Ritchie B. Assessment of human diaphragm strength and activation using phrenic nerve stimulation. Respir Physiol 1984;58:263-77.

3 Similowski T, Fleury B, Launois S, Cathala HP, Bouche P Durenne JP. Cervical magnetic stimulation: a new painless method for bilateral phrenic nerve stimulation in conscious humans. I Appl Physiol 1989;67:1311-8.

4 Wragg S, Aquilina R, Moran J, Ridding M, Hamnegard C, Fearn T, et al. Comparison of cervical magnetic and bilateral percutaneous electrical stimulation of the phrenic bilateral percutaneous electrical stimulation of the phrenic

5 Milic-Emili J, Mead J, Turner JM, Glauser EM. Improved technique for estimating pleural pressures from oesophageal balloons. F Appl Physiol 1964;19:207-11.

6 Baydur A, Pangiotis K, Behrakis K, Zin WA, Jaeger M, Emili JAM. A simple method of assessing the validity of the esophageal balloon technique. Am Rev Respir Dis 1982 126:788-91.

7 Sixt R, Bake B. A simple pressure calibrator. Scand 7 Clin Lab Invest 1976;36:1-2.

8 Wragg SD, Hamnegard CH, Kyroussis D, Road J, Green M, Moxham J. Potentiation of diaphragmatic twitch after its voluntary activation. Thorax 1994;49:1234-7.

9 Mador JM, Magalang UJ, Kufel TJ. Twitch potentiation following voluntary diaphragmatic contraction. Am $\mathcal{f}$ Respir Crit Care Med 1994;149:739-43.

10 Roussos C, Fixley M, Gross D, Macklem PT. Fatigue of inspiratory muscles and their synergistic behaviour. $\mathcal{F} A p p l$ Physiol: Respirat Environ Physiol 1979;46:879-904.

11 Miller J, Moxham J, Green M. The maximal sniff in the assessment of diaphragmatic function in man. Clin Sci 1985;69:91-6.

12 Laroche CM, Mier AK, Moxham AJ, Green M. Diaphragm strength in patients with recent hemidiaphragm paralysis. Thorax 1988;43:170.

13 Mulvey DA, Aquilina RJ, Elliot MW, Moxham J, Green M Diaphragmatic dysfunction in neuralgic amyotrophy: an electrophysiologic examination of 16 patients presenting with dyspnoea. Am Rev Respir Dis 1993;147:66-71.

14 Mier A, Brophy C, Moxham J, Green M. Assessment of diaphragm weakness. Am Rev Respir Dis 1988;137:877-83.

15 Bellemare F, Bigland-Ritchie B, Woods JJ. Contractile properties of the human diaphragm in vivo. $\mathcal{F}$ Appl Physiol 1986;53:1153-61. 